\title{
PROGRAMA TISP COMO FERRAMENTA DE DESENVOLVIMENTO PROFISSIONAL DE EDUCADORES E ESTUDANTES DE ESCOLAS PÚBLICAS DA CIDADE DE CAMPINA GRANDE
}

Márcia Lais da Silva Pontes - marcia.pontes@ee.ufcg.edu.br

Universidade Federal de Campina Grande

R. Aprígio Veloso, 882, Bairro Universitário

58429-900 - Campina Grande - Paraíba

Weverton Domingos de Medeiros - wevertonmdrs@gmail.com

Universidade Federal de Campina Grande

R. Aprígio Veloso, 882, Bairro Universitário

58429-900 - Campina Grande - Paraíba

Larissa da Silva Lima-Larissa.lima@ee.ufcg.edu.br

Universidade Federal de Campina Grande

R. Aprígio Veloso, 882, Bairro Universitário

58429-900 - Campina Grande - Paraíba

Lara Rocha Sobral-lara.sobral@ee.ufcg.edu.br

Universidade Federal de Campina Grande

R. Aprígio Veloso, 882, Bairro Universitário

58429-900 - Campina Grande - Paraíba

Hitalo Ricardo da Silva Lima - hitalo.lima@ee.ufcg.edu.br

Universidade Federal de Campina Grande

$R$. Aprígio Veloso, 882, Bairro Universitário

58429-900 - Campina Grande - Paraíba

Resumo: Neste artigo é discutida a metodologia de aplicação do programa Teach in Service Program (TISP) em escolas públicas da cidade de Campina Grande-PB, adotada pelos voluntários e membros do Ramo Estudantil IEEE UFCG (Universidade Federal de Campina Grande). O TISP é um programa proposto pelo IEEE, organização cuja missão é promover o avanço tecnológico com excelência em benefício da sociedade, cujo objetivo é desenvolver profissionalmente educadores de escolas, incentivando-os a propor novas práticas pedagógicas, na tentativa de despertar o interesse dos estudantes pelas disciplinas das áreas de Ciência, Tecnologia, Engenharia e Matemática (STEM, do inglês Science, Technology, Engineering and Mathematics) por meio de experimentos práticas utilizando materiais de baixo custo, despertando o espírito de engenheiro nos estudantes, além de promover uma reflexão sócio-ambiental sobre uso responsável de determinados materiais.

Palavras-chave: Engenharia nas escolas. Educação na prática. Desenvolvimento profissional.

\section{INTRODUÇÃO}

Ao observar a metodologia tradicional de ensino, podem ser abertas discussões e levantadas hipóteses a respeito do desinteresse e afastamento dos alunos em relação a área de 
ciências exatas. Uma dessas hipóteses é a falta de ensino por experimentação nas ciências, segundo Reis (2016).

Diante dessa realidade, a precarização do ensino básico é um dos principais fatores que justificam a discrepância no percentual de alunos que concluíram o ensino médio em escolas públicas aos alunos de escola privada (ALVARENGA, 2012), visto que as escolas públicas muitas vezes não dispõem de recursos que estimulem, deem acesso e facilitem o aprendizado dos alunos sobre as disciplinas de ciências exatas e da natureza (STROMQUIST, 2007), sendo alguns destes segurança nas escolas, práticas pedagógicas adequadas, material de apoio didático (ORTEGA, 2001). Além do mais, têm sido propostas novas metodologias de ensino, visando mudar a forma de exposição dos conteúdos das disciplinas das áreas citadas, afirma Faustino (2014). A experiência da rotina escolar é muito importante para o crescimento profissional dos alunos e professores, e a escola, como instituição de formação, se transforma ao passo que a tecnologia têm se apresentado como forte ferramenta para garantir tal crescimento, de acordo com Faustino (2014).

De acordo com a Base Nacional Comum Curricular (BNCC), as aprendizagens essenciais definidas para cada etapa da Educação Básica só se materializam mediante um conjunto de decisões, dentre as quais é possível destacar "conceber e pôr em prática situações e procedimentos para motivar e engajar os alunos nas aprendizagens", como também na garantia do cumprimento da terceira competência específica de Ciências da Natureza e suas Tecnologias para o ensino médio, "espera-se que os estudantes possam se apropriar de procedimentos e práticas das Ciências da Natureza como o aguçamento da curiosidade sobre o mundo".

Dessa forma, promover um contato com práticas experimentais dos conteúdos aprendidos em sala de maneira mais profunda desde o ensino básico (fundamental e médio), tende a proporcionar um futuro com grande potencial inovador em termos de tecnologia, conforme Cruz (2007), essa metodologia estimula o aluno a fazer descobertas de maneira diversificada e autônoma.

Nos últimos anos várias iniciativas estão sendo fomentadas no âmbito da ciência e desde então surgiram diversas formas de tornar lúdica a aprendizagem. Uma das que têm ganhado espaço pela eficiência dos resultados é a realização de experimentos práticos que envolvam os conceitos teóricos vistos em sala por meio da utilização de material de baixo custo. No Brasil, uma dessas iniciativas é realizada pelo Ramo Estudantil da organização profissional Institute of Electrical and Electronics Engineers (IEEE), com atuação na Universidade Federal de Campina Grande (UFCG). Desde 2014, este grupo desenvolve oficinas Teach in Service Program (TISP) em escolas das redes públicas. As oficinas TISP consistem no desenvolvimento profissional destinado a educadores, incentivando-os a propor novas práticas pedagógicas que apliquem, de maneira simples e didática, os conceitos de disciplinas das áreas de STEM em um contexto real, fazendo uso de materiais de baixo custo, com a finalidade de despertar o lado curioso, criativo e científico nos estudantes, além de conscientizar os alunos sobre a reutilização de materiais recicláveis para a realização das atividades.

Esse tipo de incentivo no ambiente escolar auxilia os alunos a explorarem seu próprio potencial em estudos específicos e estarem à frente em um mercado de trabalho que se mostra cada vez mais competitivo. Por fim o projeto pretende desenvolver o lado profissional dos alunos e estimular a criatividade e a proatividade e senso de responsabilidade sócio-ambiental. Sendo assim, neste trabalho será apresentada a metodologia utilizada nas oficinas TISP aplicadas nas escolas da rede pública ao longo de 6 anos. Para isso, o artigo será dividido da seguinte forma: metodologia, resultados e discussões e considerações finais. 


\section{METODOLOGIA}

Como representação do IEEE dentro da UFCG, o Ramo Estudantil IEEE UFCG tem como missão o fomento do desenvolvimento tecnológico na tentativa de impactar positivamente a comunidade. O IEEE propõe às representações estudantis e voluntários a realizarem atividades educacionais para os professores de ensino fundamental e médio. $\mathrm{O}$ TISP é programa educacional de extensão que visa melhorar o ensino das disciplinas das áreas de STEM, além de incentivar os estudantes a seguirem carreiras técnicas, a exemplo da engenharia. O programa funciona como um workshop de desenvolvimento profissional destinado a ajudar os professores a pensarem em novas metodologias de ensino por meio de aulas práticas, levando a engenharia para suas salas de aula, de modo a despertar o engenheiro que existe dentro de cada um dos estudantes.

Os ex-integrantes responsáveis pela estruturação e consolidação do programa na UFCG deixaram descritos os passos necessários a serem tomados para o sucesso da atividade que perdura até os dias atuais. Apesar de ser uma atividade proposta pelo IEEE, todo Ramo Estudantil adota uma metodologia de implementação do programa, na tentativa de alcançar o seu objetivo. A metodologia descrita abaixo é a desenvolvida e adotada atualmente pelo Ramo Estudantil IEEE UFCG.

Inicialmente, todo início de ano acontece a formação da equipe de voluntários responsáveis pela implementação da atividade, liderados por um coordenador, chamada de TISP Team. Apesar de o programa ser direcionado para professores, a equipe TISP aplica-o na comunidade acadêmica da UFCG, e em eventos estudantis, na tentativa de atrair novos entusiastas, pensando na manutenção do grupo, além de serem momentos para capacitação e aprimoramento das atividades.

Ainda no início do ano, o grupo vai às escolas públicas da cidade de Campina Grande, normalmente próximas da universidade de atuação, devido a maior facilidade de locomoção, para fechar parceria. No ato da parceria, define-se quais os professores que, voluntariamente, irão participar da atividade, as turmas e qual o período dos encontros. Haja vista a dificuldade de adaptação de alguns professores, apesar do interesse no projeto, devido a falta de flexibilização na forma de ensino, as dinâmicas de capacitação são feitas, no mesmo momento, com os professores e alunos. Assim, equipe de voluntários TISP consegue acompanhar o desenvolvimento da turma e ajudar os professoras a conduzirem as atividades, além de encorajar os professores a continuar aplicando novas metodologias em sala de aula.

A equipe TISP visita à escola parceira mensalmente, cujo propósito é a realização de atividades/experimentos, sendo esses diferentes todos os meses. Os experimentos a serem executados são escolhidos do banco de atividades TISP do IEEE, o TryEngineering, que contém a documentação detalhada sobre o que é a atividade, quais materiais podem ser utilizados pelos professores, além do alinhamento com a grade curricular das disciplinas de STEM das escolas. Essas informações analíticas sobre a atividade são de interesse apenas da equipe TISP e dos professores da escola. Para iniciar a aplicação do programa aos estudantes, os voluntários do grupo TISP realizam a divisão de todos os estudantes da sala de aula em grupos de 4 a 6 . Cada atividade exige recursos diferentes e, portanto, o tempo de execução delas difere. $\mathrm{Na}$ sequência, fazem uma apresentação sobre a atividade, com ajuda de equipamento de projeção fornecido pelo Ramo Estudantil, na tentativa de uniformizar o entendimento da turma. Após explicar como funciona a atividade, é feita a exposição de um protótipo da solução proposta como atividade, a qual deve ser feita utilizando materiais de baixo custo, acessíveis, disponibilizados pelo Ramo Estudantil. Os estudantes devem, portanto, trabalhar em equipe, usar a criatividade, se planejarem e administrar bem o tempo proposto, normalmente de 15 a 20 minutos, para apresentar o resultado final. Não existe 
prêmio para a equipe vencedora, aquela que cumpriu com os objetivos da atividade, apesar da competição saudável entre os estudantes, visto que há o aprendizado durante o processo. Ao fim da atividade, os voluntários, juntamente com o professor responsável, inicia uma discussão sobre os conceitos teóricos aplicados na prática com a atividade proposta. Os voluntários aplicam um formulário de avaliação para os estudantes e professor com o objetivo de saber se como foi a experiência.

\section{RESULTADOS E DISCUSSÕES}

Os resultados da avaliação do TISP foram obtidos por meio de questionários respondidos pelos participantes, com o intuito de saber como foi a atividade, a relevância que teve para os participantes, além de ajudar na melhoria da mesma com críticas e/ou sugestões. Os questionário foram entregues ao final de cada ciclo de atividades. Todos respondem de forma anônima, trazendo assim mais conforto nas respostas e evitando parcialidade na avaliação. As perguntas são feitas segundo o modelo apresentado na imagem 1.

Figura 1: Questionário de avaliação das atividades.
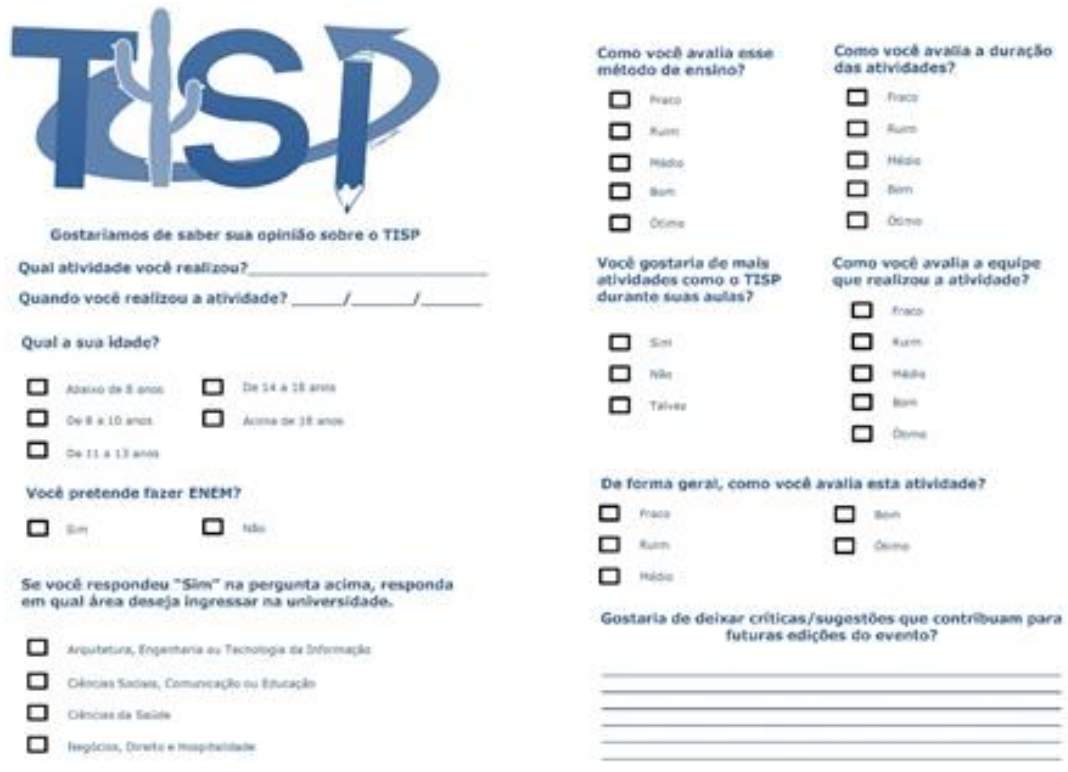

Fonte: Autoria própria.

No formulário são pedidas aos participantes, informações básicas como idade, qual o interesse em prestar o ENEM, e em qual área de estudo querem ingressar, além de perguntas para avaliação da atividade realizada. A etapa de avaliação da atividade é não obrigatória e foram obtidos os seguintes dados: 


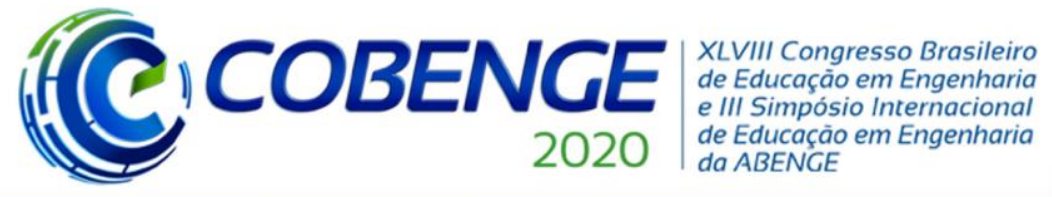

"Os desafios para formar hoje o engenheiro do amanhã"
01 a 03 de dezembro Evento On-line

Figura 2: Idade dos participantes.

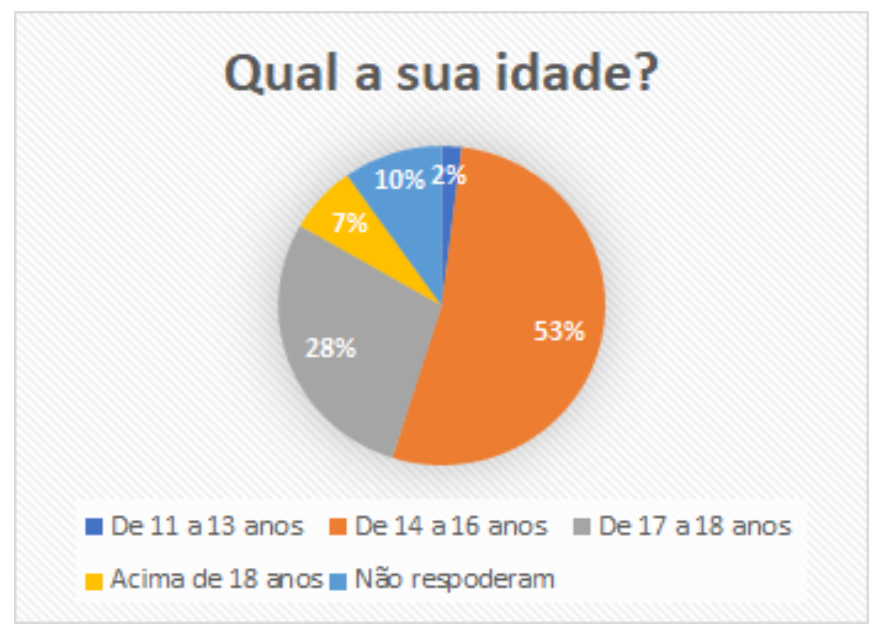

Fonte: Autoria própria.

A idade dos participantes variou desde 11 anos, a maiores de 18 anos. A maioria dos participantes tinham idades entre 14 a 18 anos.

Figura 3: Participantes que pretendem fazer ENEM e áreas que pretendem seguir.
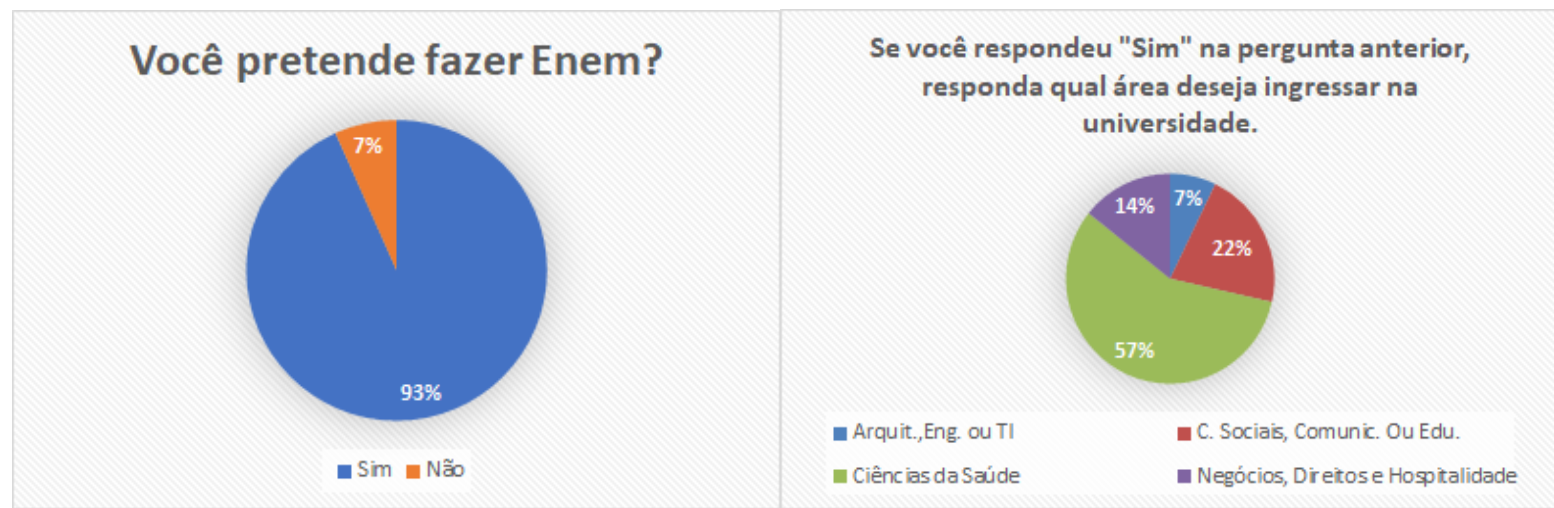

Fonte: Autoria própria.

Sobre as pessoas que pretendem fazer ENEM, a maioria respondeu que pretendem fazer, onde destes, quando foram perguntadas sobre as áreas de atuação que sentiam interesse em estudar, mais da metade dos estudantes pretendiam entrar na área de Ciências da Saúde. Enquanto que as áreas de STEM, como Arquitetura, Engenharias e Tecnologias da Informação foram as menos votadas, com apenas $7 \%$ dos votos. 
Figura 4: Avaliação do método de ensino e da duração.
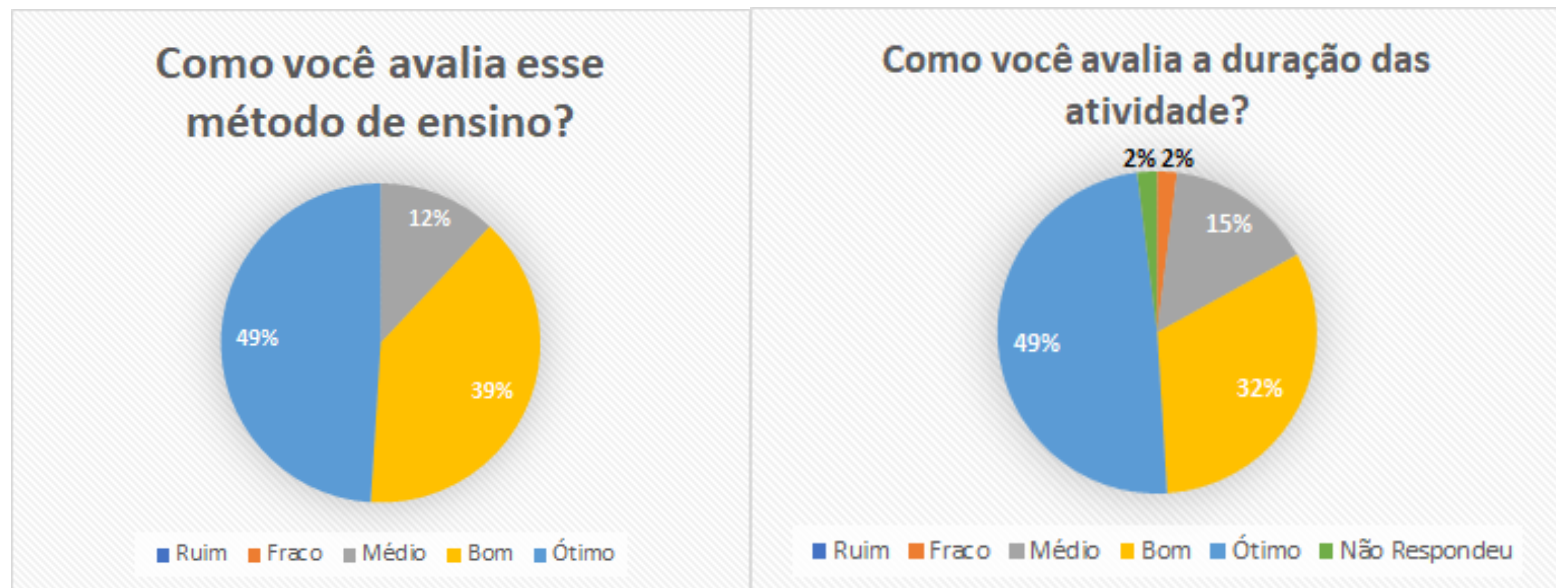

Fonte: Autoria própria.

$\mathrm{Na}$ avaliação da utilização desse método de ensino nas aulas, $49 \%$ dos participantes votaram como ótimo, $39 \%$ como bom e apenas $12 \%$ como médio. Não houve votos para fraco ou ruim. Sobre a duração $49 \%$ achou ótimo, $32 \%$ achou bom, $15 \%$ achou que foi uma duração mediana, $2 \%$ achou ruim a duração e $2 \%$ não souberam ou não quiseram responderam.

Figura 5: Repetibilidade e avaliação geral da atividade.

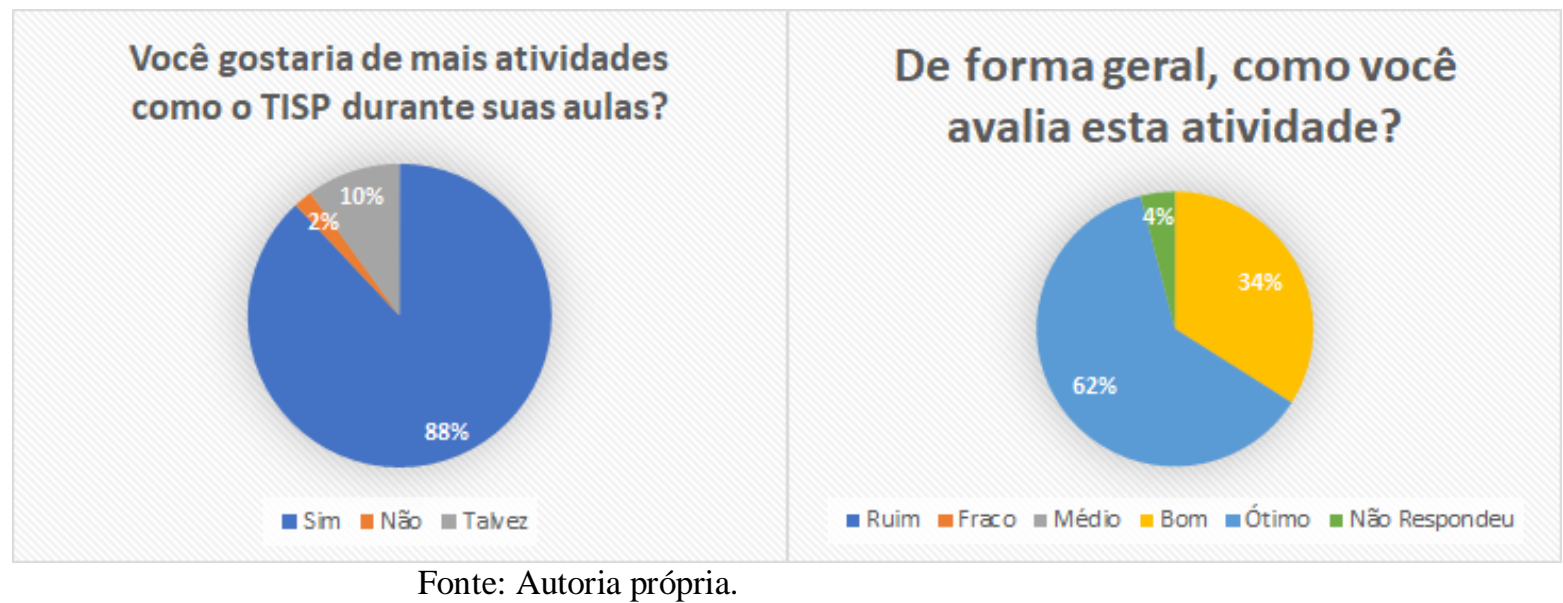

Quando o assunto foi o aumento da frequência da atividade, cerca de $88 \%$ dos participantes gostariam que fossem feitas mais aulas com essa dinâmica, mostrando que se torna uma forma atrativa de pôr em prática o que se aprende na teoria. Apenas $2 \%$ das pessoas não concordam, e $10 \%$ informou que talvez seria bom a realização da atividade mais vezes.

$\mathrm{Na}$ avaliação geral, a atividade teve um bom resultado, em que $62 \%$ acharam que foi ótimo, $34 \%$ acharam que foi boa, e $4 \%$ não souberam ou não quiseram responder. Não havendo votos para avaliação média, ruim ou fraca. Ainda no final do questionário, foi perguntado se os participantes gostariam de deixar críticas ou sugestões que contribuam para as futuras edições do evento. Dentre as mensagens, várias delas foram sobre o interesse dos estudantes de participar de mais dinâmicas TISP, como sugeriram, "Eu só queria que tivesse mais atividades do TISP no nosso colégio." "Ter mais aulas como essa na escola, e aulas mais bem explicadas.", “Ter mais vezes essas atividades porque é muito bom.”. Também pode-se 
analisar que apesar de apenas 7\% dos estudantes declararam que têm ingressar em cursos nas áreas de STEM, 62\% acharam o TISP uma ótima atividade e $34 \%$ concordou que a atividade foi boa, demonstrando como as disciplinas tornam-se interessantes quanto abordadas com uma nova metodologia. Pode-se comprovar isso também quando $88 \%$ dos alunos demonstram que gostariam que aumentasse a frequência das atividades TISP na escola.

Houveram também outras dicas, como por exemplo aplicar a metodologia em outras disciplinas, além de também aumentar a duração das mesmas. Por fim percebemos o quão impactante e importante é a atividade, pois além de estimular o aprendizado dos alunos, estimula a criatividade, participação, comunicação e o trabalho em equipe, competitividade de forma saudável e retira um pouco do bloqueio que muitos estudantes criam a respeito da disciplinas das áreas de STEM.

\section{CONSIDERAÇÕES FINAIS}

A Oficina TISP acrescentou tanto na vida dos alunos quanto na vida dos professores e dos voluntários responsáveis pelo projeto. Observa-se que, por meio das ações desenvolvidas pelo grupo, as atividades aplicadas em cada oficina funcionaram como ferramenta para aproximar os alunos de soluções e experimentos com materiais de baixo custo, estimulando a conscientização da necessidade de promover sustentabilidade, além de que funcionaram como agentes agregadores na formação do conhecimento.

Tendo em vista que as oportunidades são reduzidas para os alunos nas escolas da rede pública, e não se tem muita estrutura voltada para as áreas de STEM, projetos como esses são bastante importantes, pois se mostram como algo inovador, dinâmico e estimulante desenvolvendo as habilidades e criatividade dos alunos. Uma vez que essa realidade foi exposta para toda comunidade da escola parceira, também foi dada a iniciativa para que mais atividades como essas fossem estimuladas.

Assim, a metodologia de execução desse projeto foi idealizada por voluntários do Ramo Estudantil IEEE UFCG como forma de contribuir com a execução da Base Nacional Comum Curricular, bem como melhorar a prática de aprendizagem dos alunos de ensino médio das redes públicas nas áreas de exatas realizando roteiros experimentais para tornar mais lúdicas as formas de aprendizagem.

\section{Agradecimentos}

Muitas pessoas já passaram pelo Ramo Estudantil e pelo TISP Team ao longo dos anos, garantindo continuidade, crescimento e aperfeiçoamento dessa atividade, sendo esse artigo, portanto, fruto do trabalho de todos os voluntários que atuaram e/ou ainda são atuantes no projeto TISP, em especial às pessoas que, ainda em 2014 enxergaram o potencial que esse programa, proposto pelo IEEE, tem e como poderia ser utilizado para transformar vidas, sejam a dos próprios voluntários ou dos participantes diretamente impactados, os estudantes e educadores. Nosso muito obrigado a Iago Batista, Lucas Tavares, Luiza Araújo, Maria Clara Magalhães, Maria Fernanda, Milena Arruda, Natã Macêdo, Paulo Gustavo, Reiron Lopes, Safire Torres e Túlio Araújo. Agradecemos também a todos os nossos voluntários que ajudaram na execução, inovação e melhoria do programa.

\section{REFERÊNCIAS}

ALVARENGA, Carolina Faria, et al. "Desafios do ensino superior para estudantes de escola pública: um estudo na UFLA." Revista Pensamento Contemporâneo em Administração 6.1 
(2012): 55-71.

Base Nacional Comum Curricular - Educação é a Base. Disponível em: Base Nacional Comum Curricular - Educação é a Base. Disponível em: <http://basenacionalcomum.mec.gov.br/abase/>. Acesso em 01 de junho de 2020.

CRUZ, Joelma Bomfim da. Laboratórios. / Joelma Bomfim da Cruz. - Brasília : Universidade de Brasília, 2007. Disponível em:

$<$ http://portal.mec.gov.br/seb/arquivos/pdf/profunc/13_laboratorios.pdf $>$. Acesso em $01 \mathrm{de}$ junho de 2020.

FAUSTINO, Aline de Lima. "Ações inovadoras no âmbito escolar: o caso da Gincana da Física e o curso de Iniciação Científica no Ensino Médio.” (2014).

OECD - Education at a Glance 2019. Disponíel em: <https://www.oecd.org/education/education-at-a-glance/>. Acesso em 01 de junho de 2020.

ORTEGA, Eliane Maria V. O ensino médio público e o acesso ao ensino superior. Estudos em Avaliação Educacional. São Paulo, Fundação Carlos Chagas, n. 23, p. 153-176, jan./jun.2001.

REIS, Ana Paula dos. Dificuldades dos estudantes nas disciplinas de exatas do ensino médio. 2016. Disponível em:

<http://bdm.unb.br/bitstream/10483/14121/1/2016_AnaPauladosReis_tcc.pdf $>$. Acesso em 01 de

junho de 2020 .

STROMQUIST, Nelly P. "A desigualdade como meio de vida: educação e classe social na América Latina.” Revista brasileira de estudos pedagógicos 85.209-10-11 (2007).

Todos pela educação; Editora Moderna. Anuário Brasileiro da Educação Básica 2019. São Paulo, 2019.2 Disponível em: <https://www.todospelaeducacao.org.br/_uploads/_posts/302.pdf $>$. Acesso em: 01 junho 2020 .

\title{
TISP PROGRAM AS A PROFESSIONAL DEVELOPMENT TOOL FOR EDUCATORS AND STUDENTS OF PUBLIC SCHOOLS IN THE CITY OF CAMPINA GRANDE
}

\begin{abstract}
At this paper is discussed the methodology applied for Teach in Service Program (TISP), that happens in public schools in Campina Grande-PB by IEEE UFCG Student Branch volunteers and members. TISP is a program proposed by IEEE, an organization whose mission is the advance technology for the benefit of humanity, which aims to develop professionally middle and high school teachers, inspiring them to create new pedagogical practices, in an attempt to arouse students' interest in STEM subject through practical experiments using low-cost materials, "awakening the soul of engineer in the students", besides promoting a socio-environmental reflection about the responsible use of some materials.
\end{abstract}


Keywords: Engineering in schools. Education in practice. Professional development. 